\title{
Extraction of Proanthocyanidins and Anthocyanins from Grape Skin by Using Ionic Liquids
}

\author{
Natka Ćurko, Marina Tomašević, Marina Cvjetko Bubalo, Leo Gracin, \\ Ivana Radojčić Redovniković and Karin Kovačević Ganić \\ University of Zagreb, Faculty of Food Technology and Biotechnology, Pierottijeva 6, \\ HR-10000 Zagreb, Croatia \\ Received: February 6, 2017 \\ Accepted: April 24, 2017
}

\begin{abstract}
Summary
In this study, eight different types of imidazolium-based ionic liquids (ILs) were applied as new solvents in the extraction of flavonoids from grape skin, and compared to the conventional organic solvent extraction that was not reported earlier. The structure of anions, cations and concentration of ILs significantly affected extraction yields. The highest mass fractions of proanthocyanidins and anthocyanins were obtained with $2.5 \mathrm{~mol} / \mathrm{L}$ of 1-butyl-3-methylimidazolium bromide $\left[\mathrm{C}_{4} \mathrm{mim}\right][\mathrm{Br}]$ and $2.5 \mathrm{~mol} / \mathrm{L}$ of 1-ethyl-3-methylimidazolium bromide $\left[\mathrm{C}_{2} \mathrm{mim}\right][\mathrm{Br}]$, respectively. The studied ILs provided an excellent preliminary result in the extraction of anthocyanins. Significantly higher mass fractions of total and all free anthocyanins were extracted with $2.5 \mathrm{~mol} / \mathrm{L}$ of $\left[\mathrm{C}_{2} \mathrm{mim}\right][\mathrm{Br}]$ and $2.5 \mathrm{~mol} / \mathrm{L}$ of 1-methylimidazolium hydrogen sulfate $[\mathrm{mim}]\left[\mathrm{HSO}_{4}\right]$ than with conventional solvent with the exception of anthocyanin-3-O-acetylmonoglucosides in the latter. On the other hand, $2.5 \mathrm{~mol} / \mathrm{L}$ of $\left[\mathrm{C}_{4} \mathrm{mim}\right][\mathrm{Br}]$ and $2.5 \mathrm{~mol} / \mathrm{L}$ of 1-(4-sulfobutyl)-3-methylimidazolium hydrogen sulfate $\left[\mathrm{sC}_{4} \mathrm{mim}\right]\left[\mathrm{HSO}_{4}\right]$ showed significantly higher selectivity towards anthocyanin-3-O-acetylmonoglucosides and anthocyanin-3-(6-O-p-coumaroyl)monoglucosides.
\end{abstract}

Key words: anthocyanins, grape skin, HPLC, ionic liquids, proanthocyanidins

\section{Introduction}

Proanthocyanidins (condensed tannins) and anthocyanins are the main phenolic compounds of grape skin, belonging to the flavonoid family. In recent years, these compounds have attracted great attention since they are responsible for major grape and wine sensory properties like mouth-feel (1-3) and colour (4), but also for their protective effect against cardiovascular risk factors due to many biological activities (5). Structurally, grape skin proanthocyanidins are polymers consisting of $(+)$-catechin, $(-)$-epicatechin, (-)-epicatechin gallate and (-)-epigallocatechin units; highly more polymerized and less galloylated than seed proanthocyanidins $(3,6)$. Anthocyanins of Vitis vinifera grape cultivars are primarily based on five major anthocyanin monoglucosides, namely delphinidin, cyanidin, petunidin, peonidin and the most abundant malvidin; with lower portions of their acetic, caffeic and $p$-coumaric acid esters $(7,8)$.

The conventional extraction of phenolic compounds most commonly implies the application of volatile, toxic and flammable organic solvents; and procedures often employing mixtures of solvents and multiple repetitions, which can be time-consuming (9). For instance, methanol, ethanol, acetone, water and their combinations are commonly used in extraction of proanthocyanidins from various plant materials (10). In addition, the two-step procedure using aqueous acetone followed by aqueous methanol represents the most common procedure used in the ex-

\footnotetext{
*Corresponding author: Phone: + 38514605 015; E-mail: iradojci@pbf.hr 
traction of overall grape proanthocyanidins $(2,3,6)$, since methanol has been shown to have great extraction efficiency towards flavan-3-ol monomers and oligomers (11), and acetone towards polymers. On the other hand, due to the stability of red flavylium cation in highly acidic media (12), the extraction of anthocyanins is commonly performed with slightly acidified organic solvents (10), namely methanol or ethanol, which are found to be more effective than water (13).

Recently, the application of ionic liquids (ILs) as greener alternatives to conventional organic solvents has been proposed $(14,15)$. ILs are organic salts in the liquid state that consist of organic cations paired with organic or inorganic anions. The unique physicochemical properties of ILs that make them interesting from technological point of view are negligible vapour pressure (reduced air pollution), non-flammability (process safety), good stability (reusability) and possibility to design an optimal IL for a specific purpose $(16,17)$. Properties like thermal stability and miscibility are mainly affected by the structure of the anion, while others, such as viscosity, surface tension and density depend on the length of the alkyl chain in the cation and/or its shape or symmetry $(18,19)$. Reports on the ecotoxicologycal profile of ILs have pointed out that toxicity of commonly used imidazolium and pyridinium ILs ranges from low to hazardous; however, environmental impact is strongly influenced by the IL structure, and as a result a great effort is being made to identify the factors that control IL behaviour. Also, the major benefit of using ILs as solvents results from their low vapour pressure and non-flammability, which surely makes them preferable to volatile and flammable organic solvents (20).

Previous studies have demonstrated promising applicability of imidazolium-based ILs in the extraction of different phenolic compounds such as phenolic acids (gallic, ellagic, chlorogenic and caffeic acids) $(21,22)$, stilbenes (trans-resveratrol) $(21,23)$, flavonols (quercetin, myricetin, kaempferol and rutin) $(21,22,24,25)$ and proanthocyanidins $(26,27)$ from various plant materials. In addition, physicochemical properties of ILs, which can be moderated and dictated by their structural characteristics of anion and cation, were also found to significantly affect extraction yields of target analytes $(21,22,27)$. For instance, the solubility of phenols in ILs was shown to depend on the ability of phenols to form intra- and intermolecular bonds, as well as the polarity of ILs (28). However, we have not observed in these reports that authors studied the application of ILs in the extraction of flavonoid compounds from the complex grape skin matrix, which requires further understanding.

The aim of this work is to study the potential of imidazolium-type ILs in the extraction of main grape skin flavonoids (proanthocyanidins and anthocyanins) by comparing them to conventional organic solvent extraction. The effect of IL anions and cations, and of their concentration on the extraction yield of grape skin flavonoids was examined.

\section{Materials and Methods}

\section{Chemicals}

Deionized water was purified with a Milli-Q water system (Millipore Corp., Bedford, MA, USA). Methanol and acetonitrile were of HPLC grade and were purchased from J.T. Baker (Deventer, the Netherlands) and Panreac (Barcelona, Spain). Ethanol, hydrochloric acid, acetone and formic acid were purchased from Carlo Erba (Rodano, Italy), and sodium bisulfite from Acros organics (Geel, Belgium). Analytical standards of delphinidin-3-O-monoglucoside, cyanidin-3-O-monoglucoside, petunidin-3-O-monoglucoside, peonidin-3-O-monoglucoside, and malvidin-3-O-monoglucoside were purchased from Polyphenols AS (Sandnes, Norway).

\section{Ionic liquids}

Ionic liquids $\left[\mathrm{C}_{2} \mathrm{mim}\right][\mathrm{Br}],\left[\mathrm{C}_{4} \mathrm{mim}\right][\mathrm{Br}],\left[\mathrm{C}_{5} \mathrm{mim}\right][\mathrm{Br}]$, $\left[\mathrm{C}_{7} \mathrm{mim}\right][\mathrm{Br}],\left[\mathrm{C}_{10} \mathrm{mim}\right][\mathrm{Br}],[\mathrm{mim}]\left[\mathrm{HSO}_{4}\right],\left[\mathrm{sC}_{4} \mathrm{mim}\right]\left[\mathrm{HSO}_{4}\right]$ and $[\mathrm{mim}]\left[\mathrm{CF}_{3} \mathrm{CO}_{2}\right]$ were prepared in different concentrations by dilution in deionized water (Table 1). Among the aforementioned ionic liquids (ILs), $[\mathrm{mim}]\left[\mathrm{HSO}_{4}\right]$ and $[\mathrm{mim}]$ $\left[\mathrm{CF}_{3} \mathrm{CO}_{2}\right]$ were purchased from Sigma-Aldrich (St. Louis, $\mathrm{MO}$, USA), while the others were synthesized. Preparation of 1-alkyl-3-methylimidazolium bromides was performed according to standard procedures (29). Preparation of $\left[\mathrm{SC}_{4} \mathrm{mim}\right]\left[\mathrm{HSO}_{4}\right]$ was performed in a two-step procedure according to literature (30). The identity of the products was confirmed by ${ }^{1} \mathrm{H}$ NMR recorded in dimethyl sulfoxide- $\mathrm{d}_{6}$ on a Varian Gem-300 spectrometer (Varian, Walnut Creek, CA, USA) at the Ruđer Bošković Institute (Zagreb, Croatia).

\section{Grape skin samples}

Grapes of the native Croatian red grape cultivar, Vitis vinifera cv. Plavac mali, originating from Dalmatia were harvested at their technological maturity in October 2012. The mass of $2 \mathrm{~kg}$ of randomly selected grapes was used for the study. Skins were immediately manually separated from the pulp, freeze-dried for three days at $-40{ }^{\circ} \mathrm{C}$ and stored at $-20^{\circ} \mathrm{C}$ before the analysis.

\section{Proanthocyanidin and anthocyanin extracts}

Grape skin proanthocyanidins and anthocyanins were extracted using conventional organic solvents and ILs. The conventional extraction of proanthocyanidins was conducted according to the procedure described by Chira et al. (3) using: (i) two-step extraction with solvent A: acetone/water ( $80: 20$ by volume) (first step), followed by extraction with solvent B: methanol/water (60:40, by volume) (second step), where centrifugation, supernatant separation and collection were applied after each extraction step; and (ii) single-step extraction with methanol/water (60:40 by volume) following the same protocol. The conventional extraction of anthocyanin extracts was conducted according to the procedure described by Lorrain et al. (31) using acidified aqueous solution of methanol (methanol/water/12 M HCl of 70:29.5:0.5 (by volume), $\mathrm{pH}=1.51$ ).

The extraction of anthocyanins and proanthocyanidins with ILs was conducted by the modified procedure of IL-based maceration extraction described by Liu et al. (24). A mass of $0.2 \mathrm{~g}$ of freeze-dried grape skin powder was weighed in an extraction tube $(15 \mathrm{~mL})$ and $5 \mathrm{~mL}$ of IL were added. The sample was vortexed for $10 \mathrm{~s}$ and placed in a shaker (Thermo Fisher Scientific, Waltham, MA, USA) for $4 \mathrm{~h}$ of extraction, at room temperature. After extraction, the sample was centrifuged for $15 \mathrm{~min}$ at $5000 \times \mathrm{g}$ 
Table 1. List of the studied ionic liquids

\begin{tabular}{|c|c|c|c|c|}
\hline Ionic liquid (abbreviation) & Cation & Anion & $c /(\mathrm{mol} / \mathrm{L})$ & $\mathrm{pH}$ \\
\hline \multicolumn{5}{|c|}{ 1-ethyl-3-methylimidazolium bromide } \\
\hline$\left[\mathrm{C}_{2} \mathrm{mim}\right][\mathrm{Br}] \_0.5 \mathrm{M}$ & & $\mathrm{Br}^{-}$ & 0.5 & 4.86 \\
\hline$\left[\mathrm{C}_{2} \mathrm{mim}\right][\mathrm{Br}] \_1.5 \mathrm{M}$ & & & 1.5 & 4.86 \\
\hline$\left[\mathrm{C}_{2} \mathrm{mim}\right][\mathrm{Br}] \_2.5 \mathrm{M}$ & & & 2.5 & 4.95 \\
\hline \multicolumn{5}{|c|}{ 1-butyl-3-methylimidazolium bromide } \\
\hline$\left[\mathrm{C}_{4} \mathrm{mim}\right][\mathrm{Br}][0.5 \mathrm{M}$ & & $\mathrm{Br}^{-}$ & 0.5 & 6.33 \\
\hline$\left[\mathrm{C}_{4} \mathrm{mim}\right][\mathrm{Br}] \_1.5 \mathrm{M}$ & & & 1.5 & 6.11 \\
\hline$\left[\mathrm{C}_{4} \mathrm{mim}\right][\mathrm{Br}] \_2.5 \mathrm{M}$ & & & 2.5 & 6.10 \\
\hline \multicolumn{5}{|c|}{ 1-pentyl-3-methylimidazolium bromide } \\
\hline$\left[\mathrm{C}_{5} \mathrm{mim}\right][\mathrm{Br}] \_0.5 \mathrm{M}$ & & $\mathrm{Br}^{-}$ & 0.5 & 6.95 \\
\hline$\left[\mathrm{C}_{5} \mathrm{mim}\right][\mathrm{Br}] \_1.5 \mathrm{M}$ & & & 1.5 & 6.90 \\
\hline$\left[\mathrm{C}_{5} \mathrm{mim}\right][\mathrm{Br}] \_2.5 \mathrm{M}$ & & & 2.5 & 6.58 \\
\hline \multicolumn{5}{|c|}{ 1-heptyl-3-methylimidazolium bromide } \\
\hline$\left[\mathrm{C}_{7} \mathrm{mim}\right][\mathrm{Br}] \_0.5 \mathrm{M}$ & & $\mathrm{Br}^{-}$ & 0.5 & 8.19 \\
\hline$\left[\mathrm{C}_{7} \mathrm{mim}\right][\mathrm{Br}] \_1.5 \mathrm{M}$ & & & 1.5 & 7.85 \\
\hline \multicolumn{5}{|c|}{ 1-decyl-3-methylimidazolium bromide } \\
\hline$\left[\mathrm{C}_{10} \mathrm{mim}\right][\mathrm{Br}] \_0.5 \mathrm{M}$ & & $\mathrm{Br}^{-}$ & 0.5 & 9.00 \\
\hline$\left[\mathrm{C}_{10} \mathrm{mim}\right][\mathrm{Br}] \_1.5 \mathrm{M}$ & & & 1.5 & 8.96 \\
\hline \multicolumn{5}{|c|}{ 1-methylimidazolium hydrogen sulfate } \\
\hline$[\mathrm{mim}]\left[\mathrm{HSO}_{4}\right] \_0.5 \mathrm{M}$ & & $\mathrm{HSO}_{4}^{-}$ & 0.5 & 1.85 \\
\hline$[\mathrm{mim}]\left[\mathrm{HSO}_{4}\right] \_1.5 \mathrm{M}$ & & & 1.5 & 1.54 \\
\hline$[\mathrm{mim}]\left[\mathrm{HSO}_{4}\right] \_2.5 \mathrm{M}$ & & & 2.5 & 1.36 \\
\hline \multicolumn{5}{|c|}{ 1-(4-sulfobutyl)-3-methylimidazolium hydrogene sulfate } \\
\hline$\left[\mathrm{sC}_{4} \mathrm{mim}\right]\left[\mathrm{HSO}_{4}\right] \_0.5 \mathrm{M}$ & & $\mathrm{HSO}_{4}^{-}$ & 0.5 & 5.35 \\
\hline$\left[\mathrm{sC}_{4} \mathrm{mim}\right]\left[\mathrm{HSO}_{4}\right] \_1.5 \mathrm{M}$ & & & 1.5 & 5.37 \\
\hline$\left[\mathrm{sC}_{4} \mathrm{mim}\right]\left[\mathrm{HSO}_{4}\right] \_2.5 \mathrm{M}$ & & & 2.5 & 5.38 \\
\hline \multicolumn{5}{|c|}{ 1-methylimidazolium trifluoroacetate } \\
\hline$[\mathrm{mim}]\left[\mathrm{CF}_{3} \mathrm{CO}_{2}\right] \_0.5 \mathrm{M}$ & & $\mathrm{CF}_{3} \mathrm{CO}_{2}^{-}$ & 0.5 & 6.30 \\
\hline$[\mathrm{mim}]\left[\mathrm{CF}_{3} \mathrm{CO}_{2}\right] \_1.5 \mathrm{M}$ & & & 1.5 & 6.45 \\
\hline$[\mathrm{mim}]\left[\mathrm{CF}_{3} \mathrm{CO}_{2}\right] \_2.5 \mathrm{M}$ & & & 2.5 & 6.50 \\
\hline
\end{tabular}

(model KL2, Fischer Bioblock Scientific, Schwerte, Germany), while the obtained supernatant was filtered. Filtered extracts of IL were further directly manipulated.

\section{Spectrophotometric analysis of total proanthocyanidins and anthocyanins}

The content of total proanthocyanidins in skin extracts was determined by the method of proanthocyanidin interflavan bond cleavage by acid hydrolysis (32). The content of total anthocyanins in skin extracts was determined by the bisulfite bleaching procedure (33). All measurements were performed on spectrometer GENESYS ${ }^{\mathrm{TM}}$ 10S (Thermo Fisher Scientific, Madison WI, USA).

\section{HPLC analysis of free anthocyanins}

The HPLC analysis was conducted on a Varian Pro Star Solvent Delivery System 230 (Varian) with a Photodi- ode Array (PDA) detector Varian Pro Star 330 (Varian), and on the Agilent 1100 Series LC-MSD system (Agilent Technologies, Waldbronn, Germany) with a PDA detector and single quadrupole mass detector equipped with electrospray ionization interface (model G1946D), where the latter was used for confirmation of peak identification. Separation was performed using a Phenomenex Nucleosil C18 column (250 mm $\times 4.6 \mathrm{~mm}, 5 \mu \mathrm{m}$; Phenomenex, Torrance, CA, USA) with column temperature set at $45^{\circ} \mathrm{C}$. The mobile phases used were solvent A: water/formic acid (95:5, by volume), and solvent B: acetonitrile/formic acid (95:5, by volume) applied at a flow rate of $1 \mathrm{~mL} / \mathrm{min}$ under the gradient conditions previously described by Lorrain et al. (31) with small modifications: 10-35\% B linear from 0-25 min, 35-100\% B linear from 25-26 min, $100 \%$ B isocratic from $26-28 \mathrm{~min}, 100-10 \%$ B linear from $28-29$ min, with the re-equilibration of the column from 29-35 min under the initial gradient conditions. UV-Vis spectra 
were measured in the wavelength range from 200 to 600 $\mathrm{nm}$. The detection was performed at $\lambda=520 \mathrm{~nm}$. The identification and peak assignment of anthocyanins were based on the comparison of their retention times, UV-Vis and mass spectral data with those of the standards and published data $(3,31)$. Quantitative determinations were performed using calibration curves of anthocynin-3-Omonoglucosides at the wavelength of maximum absorbance $(520 \mathrm{~nm})$ determined by PDA spectra. Results are converted to $\mathrm{mg}$ per $\mathrm{g}$ of skin dry mass.

\section{Data analysis}

All analyses were conducted in triplicate. Statistical data analysis was carried out with analysis of variance (ANOVA) using STATISTICA v. 7 software (34). Tukey's honestly significant difference test was used for the comparison when samples differed significantly after ANOVA $(p<0.05)$ for the analysis of polyphenols.

\section{Results and Discussion}

Structural characteristics of ionic liquids (ILs) have a significant effect on their physicochemical properties (19). Structure of anions and cations, as well as the concentration of ILs can greatly affect the extraction yields of phenolic compounds $(21-23,25-28,35)$. In order to evaluate IL performance in the extraction of main grape skin flavonoids (proanthocyanidins and anthocyanins), eight different imidazolium-based ILs varying in concentration (Table 1) were tested.

\section{Effect of ionic liquids on the extraction of grape skin proanthocyanidins}

Significant differences in the mass fraction of total proanthocyanidins obtained with selected ILs demonstrated great diversity in extraction efficiency among the studied ILs (Table 2). This was particularly pronounced for $\left[\mathrm{C}_{4} \mathrm{mim}\right][\mathrm{Br}]$ and $\left[\mathrm{C}_{10} \mathrm{mim}\right][\mathrm{Br}]$, representing the most and the least effective IL, respectively; where the mass fraction obtained in the former was $95 \%$ higher than in the latter. It is interesting to note that this finding is in agreement with the studies of Liu et al. (26) and Yang et al. (27), where $\left[\mathrm{C}_{4} \mathrm{mim}\right][\mathrm{Br}]$ was also selected as the optimal IL in the extraction of proanthocyanidins, while $\left[\mathrm{C}_{10} \mathrm{mim}\right]$ [Br] showed to be the least suitable one.

A series of 1-alkyl-3-methylimidazolium ILs with $\mathrm{Br}$ and alkyl chains ranging from $\mathrm{C}_{2}$ to $\mathrm{C}_{10}$ showed a remarkable impact of the alkyl chain length of cations on the extraction yield of grape skin proanthocyanidins (Table 2). Similarly as previously observed by other authors $(26,27)$, increasing the alkyl chain length from ethyl to butyl slightly enhanced the extraction efficiency of proanthocyanidins, while on the contrary, further increase from butyl to decyl caused a drastic decrease. Moreover, this effect was also noticed in the extraction yield of other phenolic compounds from various plant matrices $(21,22,35)$. It has been shown that the increase in the alkyl chain length of 1-alkyl-3-methylimidazolium cation decreases the surface tension and increase the viscosity and hydrophobicity of ILs (19). Therefore, it is possible that more hydrophilic ILs like $\left[\mathrm{C}_{4} \mathrm{mim}\right][\mathrm{Br}]$ interact more strongly with proanthocy-
Table 2. Effect of conventional solvent and ionic liquids on the extraction of total proanthocyanidins from grape skin

\begin{tabular}{|c|c|}
\hline Solvent & $w$ (total proanthocyanidins)/(mg/g) \\
\hline $\mathrm{CH}_{3} \mathrm{OH} / \mathrm{H}_{2} \mathrm{O}(60: 40)$ & $(99.1 \pm 0.8)^{j}$ \\
\hline $\mathrm{C}_{2} \mathrm{H}_{6} \mathrm{CO} / \mathrm{H}_{2} \mathrm{O}(80: 20)$ & $(218.4 \pm 1.2)^{\mathrm{n}}$ \\
\hline \multicolumn{2}{|l|}{$\mathrm{CH}_{3} \mathrm{OH} / \mathrm{H}_{2} \mathrm{O}(60: 40)$} \\
\hline$\left[\mathrm{C}_{2} \mathrm{mim}\right][\mathrm{Br}] \_0.5 \mathrm{M}$ & $(52.1 \pm 2.3)^{\mathrm{d}}$ \\
\hline$\left[\mathrm{C}_{2} \mathrm{mim}\right][\mathrm{Br}] \_1.5 \mathrm{M}$ & $(91.9 \pm 2.0)^{j}$ \\
\hline$\left[\mathrm{C}_{2} \mathrm{mim}\right][\mathrm{Br}] \_2.5 \mathrm{M}$ & $(129.9 \pm 2.3)^{\mathrm{lm}}$ \\
\hline$\left[\mathrm{C}_{4} \mathrm{mim}\right][\mathrm{Br}] \_0.5 \mathrm{M}$ & $(60.1 \pm 1.3)^{\text {ef }}$ \\
\hline$\left[\mathrm{C}_{4} \mathrm{mim}\right][\mathrm{Br}] \_1.5 \mathrm{M}$ & $(129.1 \pm 1.4)^{1}$ \\
\hline$\left[\mathrm{C}_{4} \mathrm{mim}\right][\mathrm{Br}] \_2.5 \mathrm{M}$ & $(137.0 \pm 0.8)^{\mathrm{m}}$ \\
\hline$\left[\mathrm{C}_{5} \mathrm{mim}\right][\mathrm{Br}][0.5 \mathrm{M}$ & $(41.3 \pm 2.9)^{c}$ \\
\hline$\left[\mathrm{C}_{5} \mathrm{mim}\right][\mathrm{Br}] \_1.5 \mathrm{M}$ & $(95.4 \pm 0.8)^{j}$ \\
\hline$\left[\mathrm{C}_{5} \mathrm{mim}\right][\mathrm{Br}] \_2.5 \mathrm{M}$ & $(110.4 \pm 4.4)^{\mathrm{k}}$ \\
\hline$\left[\mathrm{C}_{7} \mathrm{mim}\right][\mathrm{Br}] \_0.5 \mathrm{M}$ & $(38.6 \pm 2.7)^{c}$ \\
\hline$\left[\mathrm{C}_{7} \mathrm{mim}\right][\mathrm{Br}] \_1.5 \mathrm{M}$ & $(76.0 \pm 0.3)^{\mathrm{h}}$ \\
\hline$\left[\mathrm{C}_{10} \mathrm{mim}\right][\mathrm{Br}] \_0.5 \mathrm{M}$ & $(6.6 \pm 0.8)^{\mathrm{a}}$ \\
\hline$\left[\mathrm{C}_{10} \mathrm{mim}\right][\mathrm{Br}] \_1.5 \mathrm{M}$ & $(15.7 \pm 0.8)^{\mathrm{b}}$ \\
\hline$[\mathrm{mim}]\left[\mathrm{HSO}_{4}\right] \_0.5 \mathrm{M}$ & $(56.7 \pm 1.4)^{\mathrm{de}}$ \\
\hline$[\mathrm{mim}]\left[\mathrm{HSO}_{4}\right] \_1.5 \mathrm{M}$ & $(66.6 \pm 0.7)^{\mathrm{fg}}$ \\
\hline$[\mathrm{mim}]\left[\mathrm{HSO}_{4}\right] \_2.5 \mathrm{M}$ & $(84.6 \pm 0.9)^{\mathrm{i}}$ \\
\hline$\left[\mathrm{sC}_{4} \mathrm{mim}\right]\left[\mathrm{HSO}_{4}\right] \_0.5 \mathrm{M}$ & $(55.0 \pm 0.7)^{\mathrm{de}}$ \\
\hline$\left[\mathrm{sC}_{4} \mathrm{mim}\right]\left[\mathrm{HSO}_{4}\right] \_1.5 \mathrm{M}$ & $(70.3 \pm 0.3)^{\mathrm{gh}}$ \\
\hline$\left[\mathrm{sC}_{4} \mathrm{mim}\right]\left[\mathrm{HSO}_{4}\right] \_2.5 \mathrm{M}$ & $(106.8 \pm 3.3)^{\mathrm{k}}$ \\
\hline$[\mathrm{mim}]\left[\mathrm{CF}_{3} \mathrm{CO}_{2}\right] \_0.5 \mathrm{M}$ & $(15.9 \pm 0.9)^{\mathrm{b}}$ \\
\hline$[\mathrm{mim}]\left[\mathrm{CF}_{3} \mathrm{CO}_{2}\right] \_1.5 \mathrm{M}$ & $(17.0 \pm 0.3)^{\mathrm{b}}$ \\
\hline$[\mathrm{mim}]\left[\mathrm{CF}_{3} \mathrm{CO}_{2}\right] \_2.5 \mathrm{M}$ & $(21.7 \pm 1.0)^{\mathrm{b}}$ \\
\hline
\end{tabular}

Data are presented as average value of three repetitions \pm standard deviation $(N=3)$. ANOVA was used to compare the data; different letters indicate statistical differences between different solvents (Tukey's test, $\mathrm{p}<0.05$ )

anidins and thus extract the higher mass fractions of these compounds. However, among protic-based ILs (Table 2), extraction yields of total proanthocyanidins decreased in the order: $\left[\mathrm{SC}_{4} \mathrm{mim}\right]\left[\mathrm{HSO}_{4}\right]>[\mathrm{mim}]\left[\mathrm{HSO}_{4}\right]>[\mathrm{mim}]\left[\mathrm{CF}_{3} \mathrm{CO}_{2}\right]$. These protic-based ILs generally extracted lower mass fractions of total proanthocyanidins than the two most efficient ILs containing $\mathrm{Br}^{-}:\left[\mathrm{C}_{2} \mathrm{mim}\right][\mathrm{Br}]$ and particularly $\left[\mathrm{C}_{4} \mathrm{mim}\right][\mathrm{Br}]$. This was especially pronounced in $[\mathrm{mim}]$ $\left[\mathrm{CF}_{3} \mathrm{CO}_{2}\right]$, where the obtained values were very close to the lowest ones determined in $\left[\mathrm{C}_{10} \mathrm{mim}\right][\mathrm{Br}]$. These results were in accordance with the earlier research $(26,27)$, which has likewise shown that ILs based on $\mathrm{Br}^{-}$were also the most efficient in the extraction yield of proanthocyanidins.

Furthermore, extraction yields of total proanthocyanidins were significantly enhanced $(p<0.05)$ when concentrations of all ILs were increased from 0.5 to $2.5 \mathrm{~mol} / \mathrm{L}$, except for $[\mathrm{mim}]\left[\mathrm{CF}_{3} \mathrm{CO}_{2}\right]$, when this increase was negligible. The same trend was noticed earlier by other authors, indicating that the extraction efficiency of proanthocyanidins from the Larix gmelinii bark with $\left[\mathrm{C}_{4} \mathrm{mim}\right]$ [Br] increased in the concentration range of $0.25-1.25$ 
$\mathrm{mol} / \mathrm{L}$ (27). However, extraction with the same IL at concentrations higher than $0.5 \mathrm{~mol} / \mathrm{L}(0.75-1.25 \mathrm{~mol} / \mathrm{L}) \mathrm{did}$ not significantly enhance proanthocyanidin extraction from Cortex cinnamomi (26). Still, previous studies demonstrated that the concentration of each different substrate should be optimized. For example, the extraction yield of rutin from two different medical plants with $\left[\mathrm{C}_{4} \mathrm{mim}\right][\mathrm{Br}]$ reached the top at two different concentrations, amounting to 1.5 and $2.5 \mathrm{~mol} / \mathrm{L}$, respectively (25). In addition, decreased yield at the above mentioned values was attributed to greater viscosity and poorer diffusion capacity of ILs at higher concentrations. A similar pattern was also noticed in our experiment, where extraction with 2.5 $\mathrm{mol} / \mathrm{L}$ of $\left[\mathrm{C}_{7} \mathrm{mim}\right][\mathrm{Br}]$ and $\left[\mathrm{C}_{10} \mathrm{mim}\right][\mathrm{Br}]$ could not be performed due to high viscosity and poor penetration into the plant tissue. Finally, taking into account structural parameters and concentration, $2.5 \mathrm{~mol} / \mathrm{L}$ of $\left[\mathrm{C}_{4} \mathrm{mim}\right][\mathrm{Br}]$ showed the best efficiency in the extraction of total proanthocyanidins from grape skin among all studied ILs.

The comparison of ILs with conventional proanthocyanidin extraction procedures including organic solvents was also performed (Table 2). It is important to note that significantly higher mass fractions of total proanthocyanidins $(\mathrm{p}<0.05)$ were extracted with 1.5 and 2.5 $\mathrm{mol} / \mathrm{L}$ of $\left[\mathrm{C}_{4} \mathrm{mim}\right][\mathrm{Br}]$ as well as $2.5 \mathrm{~mol} / \mathrm{L}$ of $\left[\mathrm{C}_{2} \mathrm{mim}\right][\mathrm{Br}]$, $\left[\mathrm{C}_{5} \mathrm{mim}\right][\mathrm{Br}]$ and $\left[\mathrm{sC}_{4} \mathrm{mim}\right]\left[\mathrm{HSO}_{4}\right]$ than with aqueous methanol. However, the mass fraction of total proanthocyanidins extracted in the two-step conventional procedure using aqueous acetone followed by aqueous methanol was significantly higher $(p<0.05)$ than with methanol and all ILs. These results confirmed the superiority of the two-step conventional procedure and the necessity to combine different organic solvents in the extraction of proanthocyanidins. Nevertheless, further possibilities of replacing the two-step conventional procedure including organic solvents with the single-step extraction using ILs should be examined.

\section{Effect of ionic liquids on the extraction of grape skin anthocyanins}

Herein, the capacity of ILs to extract anthocyanins was shown to be structure-dependent, similarly as earlier estimated for proanthocyanidins. The evident effect of the alkyl chain length of imidazolium cation, as well as the effect of the IL anion structure on the extraction yield of grape skin anthocyanins was observed (Table 3). For instance, the elongation of cation alkyl chain from ethyl to decyl led to a significant decrease in the mass fraction of extracted total anthocyanins. These results might be attributed to two important factors occurring with the increase of chain length: first, the increase of hydrophobicity (19), causing poorer diffusion capacity of the solution; and second, the increase of $\mathrm{pH}$ value up to 9.00 inducing the degradation of anthocyanins (12). The lack of increase in the extraction efficiency of total anthocyanins from $C_{2}$ to $\mathrm{C}_{4}$ of 1-alkyl-3-methylimidazolium cation, contrary to observations previously reported by numerous authors on various phenolic compounds $(21,22,26,27,35)$ and contrary to our results for total proanthocyanidins, is probably associated with higher $\mathrm{pH}$ values of $\left[\mathrm{C}_{4} \mathrm{mim}\right][\mathrm{Br}] \mathrm{com}$ pared to $\left[\mathrm{C}_{2} \mathrm{mim}\right][\mathrm{Br}]$. In fact, anthocyanins can be found in different chemical forms depending on the $\mathrm{pH}$ of the solution $(4,12)$. At $\mathrm{pH}=1$ they are predominantly present
Table 3. Effect of conventional solvent and ionic liquids on the extraction of total anthocyanins from grape skin

\begin{tabular}{|c|c|}
\hline Solvent & $w($ total anthocyanins $) /(\mathrm{mg} / \mathrm{g})$ \\
\hline $\mathrm{CH}_{3} \mathrm{OH} / \mathrm{H}_{2} \mathrm{O} / \mathrm{HCl}(70: 29.5: 0.5)$ & $(16.2 \pm 0.3)^{\mathrm{fg}}$ \\
\hline$\left[\mathrm{C}_{2} \mathrm{mim}\right][\mathrm{Br}] \_0.5 \mathrm{M}$ & $(14.1 \pm 0.3)^{\mathrm{e}}$ \\
\hline$\left[\mathrm{C}_{2} \mathrm{mim}\right][\mathrm{Br}] \_1.5 \mathrm{M}$ & $(16.4 \pm 0.1)^{\mathrm{fg}}$ \\
\hline$\left[\mathrm{C}_{2} \mathrm{mim}\right][\mathrm{Br}] \_2.5 \mathrm{M}$ & $(17.9 \pm 0.2)^{\mathrm{h}}$ \\
\hline$\left[\mathrm{C}_{4} \mathrm{mim}\right][\mathrm{Br}] \_0.5 \mathrm{M}$ & $(13.8 \pm 0.3)^{\mathrm{de}}$ \\
\hline$\left[\mathrm{C}_{4} \mathrm{mim}\right][\mathrm{Br}] \_1.5 \mathrm{M}$ & $(15.8 \pm 0.2)^{\mathrm{f}}$ \\
\hline$\left[\mathrm{C}_{4} \mathrm{mim}\right][\mathrm{Br}] \_2.5 \mathrm{M}$ & $(15.9 \pm 0.1)^{\mathrm{f}}$ \\
\hline$\left[\mathrm{C}_{5} \mathrm{mim}\right][\mathrm{Br}] \_0.5 \mathrm{M}$ & $(13.2 \pm 0.1)^{\mathrm{cd}}$ \\
\hline$\left[\mathrm{C}_{5} \mathrm{mim}\right][\mathrm{Br}] \_1.5 \mathrm{M}$ & $(13.8 \pm 0.2)^{\mathrm{de}}$ \\
\hline$\left[\mathrm{C}_{5} \mathrm{mim}\right][\mathrm{Br}] \_2.5 \mathrm{M}$ & $(13.9 \pm 0.1)^{\mathrm{de}}$ \\
\hline$\left[\mathrm{C}_{7} \mathrm{mim}\right][\mathrm{Br}] \_0.5 \mathrm{M}$ & $(12.9 \pm 0.2)^{c}$ \\
\hline$\left[\mathrm{C}_{7} \mathrm{mim}\right][\mathrm{Br}] \_1.5 \mathrm{M}$ & $(13.2 \pm 0.2)^{\mathrm{cd}}$ \\
\hline$\left[\mathrm{C}_{10} \mathrm{mim}\right][\mathrm{Br}] \_0.5 \mathrm{M}$ & $(4.5 \pm 0.1)^{\mathrm{a}}$ \\
\hline$\left[\mathrm{C}_{10} \mathrm{mim}\right][\mathrm{Br}] \_1.5 \mathrm{M}$ & $(4.1 \pm 0.2)^{\mathrm{a}}$ \\
\hline$[\mathrm{mim}]\left[\mathrm{HSO}_{4}\right] \_0.5 \mathrm{M}$ & $(13.8 \pm 0.1)^{\mathrm{de}}$ \\
\hline$[\mathrm{mim}]\left[\mathrm{HSO}_{4}\right] \_1.5 \mathrm{M}$ & $(16.2 \pm 0.2)^{\mathrm{fg}}$ \\
\hline$[\mathrm{mim}]\left[\mathrm{HSO}_{4}\right] \_2.5 \mathrm{M}$ & $(16.9 \pm 0.2)^{g}$ \\
\hline$\left[\mathrm{sC}_{4} \mathrm{mim}\right]\left[\mathrm{HSO}_{4}\right] \_0.5 \mathrm{M}$ & $(13.8 \pm 0.3)^{\mathrm{de}}$ \\
\hline$\left[\mathrm{sC}_{4} \mathrm{mim}\right]\left[\mathrm{HSO}_{4}\right] \_1.5 \mathrm{M}$ & $(15.9 \pm 0.1)^{\mathrm{f}}$ \\
\hline$\left[\mathrm{sC}_{4} \mathrm{mim}\right]\left[\mathrm{HSO}_{4}\right] \_2.5 \mathrm{M}$ & $(16.4 \pm 0.1)^{\mathrm{fg}}$ \\
\hline$[\mathrm{mim}]\left[\mathrm{CF}_{3} \mathrm{CO}_{2}\right] \_0.5 \mathrm{M}$ & $(8.7 \pm 0.2)^{b}$ \\
\hline$[\mathrm{mim}]\left[\mathrm{CF}_{3} \mathrm{CO}_{2}\right] \_1.5 \mathrm{M}$ & $(8.4 \pm 0.1)^{\mathrm{b}}$ \\
\hline$[\mathrm{mim}]\left[\mathrm{CF}_{3} \mathrm{CO}_{2}\right] \_2.5 \mathrm{M}$ & $(8.7 \pm 0.2)^{\mathrm{b}}$ \\
\hline
\end{tabular}

Data are presented as average value of three repetitions \pm standard deviation $(N=3)$. ANOVA was used to compare the data; different letters indicate statistical differences between different solvents (Tukey's test, $\mathrm{p}<0.05$ )

in the form of red flavylium cation, and at $\mathrm{pH}$ between 2 and 4 as blue quinoidal species. At pH between 5 and 6 colourless carbinol pseudobase and chalcone were observed, while at $\mathrm{pH}$ values higher than 7 anthocyanins are degraded. Knowing that the $\mathrm{pH}$ has great importance for anthocyanin equilibrium forms and stability, it was no surprise that among 1-alkyl-3-methylimidazolium ILs, $\left[\mathrm{C}_{2} \mathrm{mim}\right][\mathrm{Br}]$ with the lowest $\mathrm{pH}$ value obtained the highest mass fraction of total anthocyanins. In addition, this IL showed the best extraction performance among all, confirming the dominance of $\mathrm{Br}^{-}$towards anthocyanins, similarly as earlier indicated for proanthocyanidins. However, mass fractions of total anthocyanins obtained in $\left[\mathrm{sC}_{4} \mathrm{mim}\right]$ $\left[\mathrm{HSO}_{4}\right]$ and particularly in $[\mathrm{mim}]\left[\mathrm{HSO}_{4}\right]$ characterized by very low $\mathrm{pH}$ values were similar or only slightly lower than those in $\left[\mathrm{C}_{2} \mathrm{mim}\right][\mathrm{Br}]$ but higher than the ones found in $\left[\mathrm{C}_{4} \mathrm{mim}\right][\mathrm{Br}]$. Therefore, these two protic ILs containing $\left[\mathrm{HSO}_{4}\right]$ anion showed to be more suitable for the extraction of anthocyanins than proanthocyanidins.

The concentration of ILs was found to be a less important parameter affecting extraction yields of anthocyanins from grape skins than the structure of cation or anion. In general, the increase in the IL concentration range from 0.5 to $2.5 \mathrm{~mol} / \mathrm{L}$ only slightly contributed to extrac- 
tion yields of anthocyanins (Table 3). This effect was to a much lesser extent than shown in our results for proanthocyanidins. The less efficient ILs, $[\mathrm{mim}]\left[\mathrm{CF}_{3} \mathrm{CO}_{2}\right]$ and especially $\left[\mathrm{C}_{10} \mathrm{mim}\right][\mathrm{Br}]$, even showed a decrease in the function of concentration, the latter possibly due to higher viscosity (19). A significant increase in extraction efficiency $(\mathrm{p}<0.05)$ with the increase of concentration was evident only with $\left[\mathrm{C}_{2} \mathrm{mim}\right][\mathrm{Br}]$. In addition, $2.5 \mathrm{~mol} / \mathrm{L}$ of $\left[\mathrm{C}_{2} \mathrm{mim}\right]$ [Br] showed the best efficiency in the extraction of grape skin anthocyanins among all ILs tested in this study.

a)

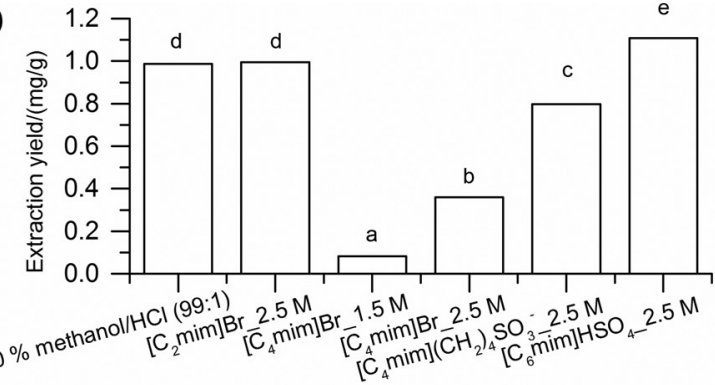

c)

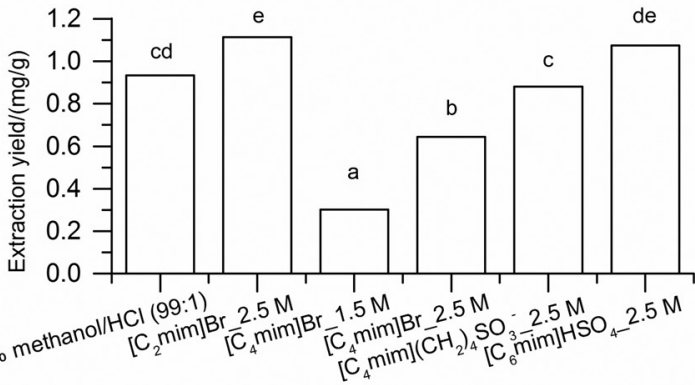

e)
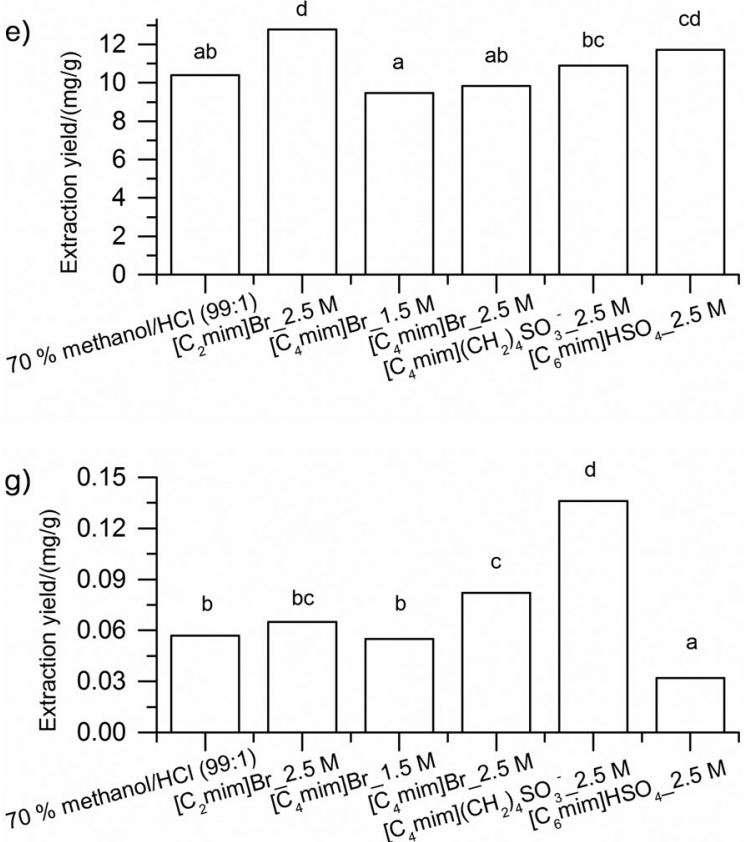

Compared with the aqueous solution of methanol, $2.5 \mathrm{~mol} / \mathrm{L}$ solution of $\left[\mathrm{C}_{2} \mathrm{mim}\right][\mathrm{Br}]$ showed significantly higher $(\mathrm{p}<0.05)$ extraction yield of total anthocyanins, while slightly higher mass fractions were obtained with $2.5 \mathrm{~mol} / \mathrm{L}$ solutions of $[\mathrm{mim}]\left[\mathrm{HSO}_{4}\right]$ and $\left[\mathrm{sC}_{4} \mathrm{mim}\right]\left[\mathrm{HSO}_{4}\right]$. Our results indicate that ILs can constitute a useful matrix to incorporate flavylium compounds $(36,37)$. Moreover, selected ILs could be used as an alternative for volatile organic solvents in extraction of anthocyanins from grape skin.
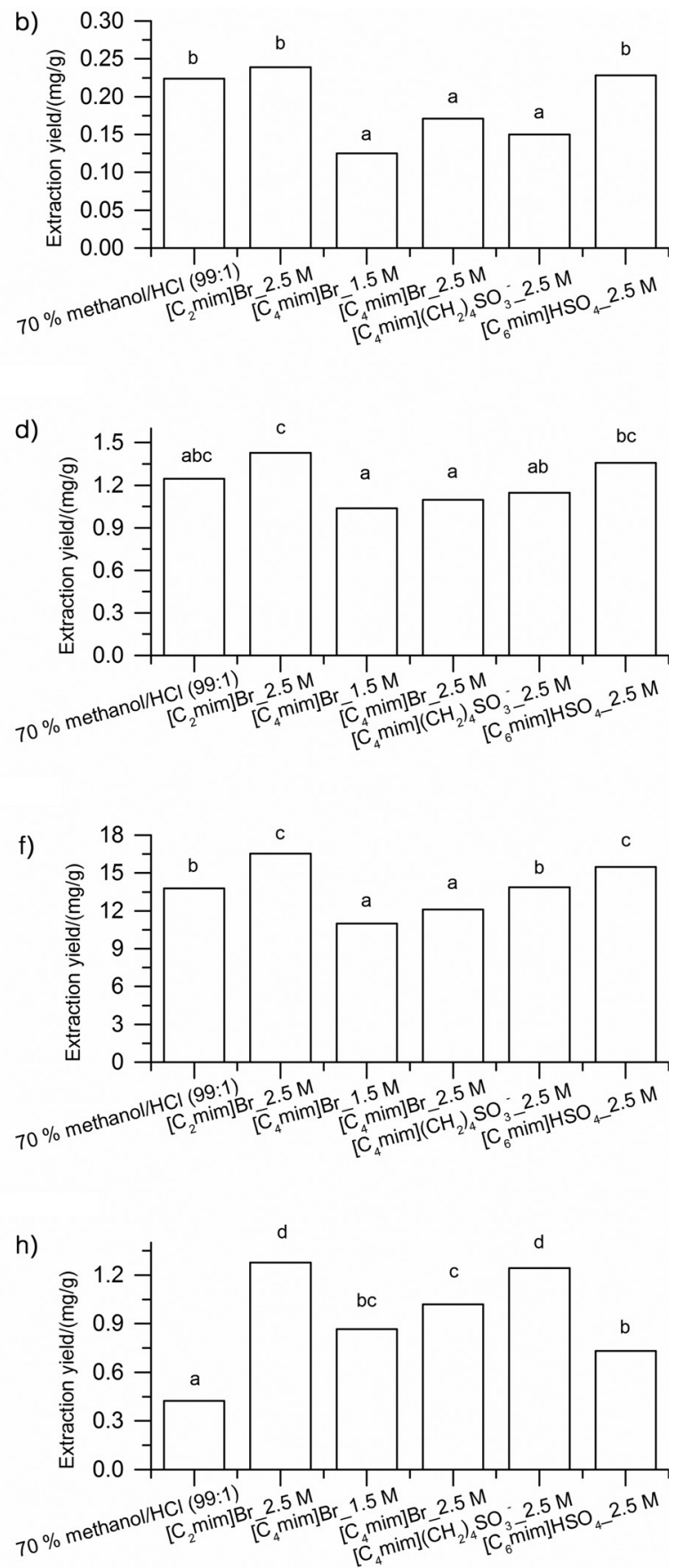

Fig. 1. Effect of conventional solvent and ionic liquids on the extraction of major free anthocyanins from grape skin: a) delphinidin-3-O-monoglucoside, b) cyanidin-O-monoglucoside, c) petunidin-3-O-monoglucoside, d) peonidin-3-O-monoglucoside, e) malvidin-3-O-monoglucoside, f) sum of anthocyanin-3-O-monoglucosides, g) sum of anthocyanin-3-O-acetylmonoglucosides, and h) sum of anthocyanin-3-(6-O- $p$-coumaroyl)monoglucosides 
Since we obtained promising results, the HPLC analysis of individual free anthocyanins was further performed in order to get more detailed information about the IL extraction selectivity. Four ILs at the concentration of $2.5 \mathrm{~mol} / \mathrm{L}$ that showed the highest extraction yields of total anthocyanins, decreasing in the order: $\left[\mathrm{C}_{2} \mathrm{mim}\right][\mathrm{Br}]>$ $[\mathrm{mim}]\left[\mathrm{HSO}_{4}\right]>\left[\mathrm{SC}_{4} \mathrm{mim}\right]\left[\mathrm{HSO}_{4}\right]>\left[\mathrm{C}_{4} \mathrm{mim}\right][\mathrm{Br}]$, were selected and compared to the conventional procedure. Anthocyanin-3-O-monoglucosides (delphinidin, cyanidin, petunidin, peonidin and malvidin) (Figs. 1a-e), their sum (Fig. 1f), as well as the sum of their major acylated derivatives (acetylmonoglucosides and $p$-coumaroylmonoglucosides of peonidin and malvidin) (Figs. $1 \mathrm{~g}$ and $\mathrm{h}$ ) were determined in selected extracts.

Some trends observed among different solvents concerning individual anthocyanin-3-O-monoglucosides (Fig. 1a-e) were very similar to the ones noticed earlier for total anthocyanins. For example, $2.5 \mathrm{~mol} / \mathrm{L}$ of $\left[\mathrm{C}_{2} \mathrm{mim}\right][\mathrm{Br}]$ and $[\mathrm{mim}]\left[\mathrm{HSO}_{4}\right]$ ILs extracted significantly higher mass fractions of all free anthocyanin-3-O-monoglucosides than 2.5 $\mathrm{mol} / \mathrm{L}$ of $\left[\mathrm{sC}_{4} \mathrm{mim}\right]\left[\mathrm{HSO}_{4}\right]$ and $\left[\mathrm{C}_{4} \mathrm{mim}\right][\mathrm{Br}] \mathrm{ILs}$. Furthermore, $2.5 \mathrm{~mol} / \mathrm{L}$ of $\left[\mathrm{C}_{4} \mathrm{mim}\right][\mathrm{Br}]$ showed the lowest extraction yields of all free anthocyanin-3-O-monoglucosides (Figs. $1 \mathrm{a}$ and $\mathrm{c}-\mathrm{e}$ ), except for cyanidin-3-O-monoglucoside (Fig. $1 b)$, where this IL was more efficient than $2.5 \mathrm{~mol} / \mathrm{L}$ of $\left[\mathrm{sC}_{4} \mathrm{mim}\right]\left[\mathrm{HSO}_{4}\right]$. In addition, efficiency of $\left[\mathrm{SC}_{4} \mathrm{mim}\right]$ $\left[\mathrm{HSO}_{4}\right]$ for the extraction of delphinidin-3-O-monoglucoside (Fig. 1a) and petunidin-3-O-monoglucoside (Fig. 1c) was much higher than that of peonidin-3-O-monoglucoside (Fig. 1d) and malvidin-3-O-monoglucoside (Fig. 1e) since the mass fractions of the first two aforementioned free anthocyanin-3-O-monoglucosides extracted by 2.5 $\mathrm{mol} / \mathrm{L}$ of $\left[\mathrm{sC}_{4} \mathrm{mim}\right]\left[\mathrm{HSO}_{4}\right]$ were significantly higher (Figs. $1 \mathrm{a}$ and c). Also, $2.5 \mathrm{~mol} / \mathrm{L}$ of $\left[\mathrm{C}_{2} \mathrm{mim}\right][\mathrm{Br}]$ and $2.5 \mathrm{~mol} / \mathrm{L}$ of [mim] $\left[\mathrm{HSO}_{4}\right]$ always yielded higher mass fractions, particularly of petunidin-3-O-monoglucoside (Fig. 1c) and the most abundant malvidin-3-O-monoglucoside (Fig. $1 \mathrm{e})$, increasing it in the overall sum of anthocyanin-3-O-monoglucosides (Fig. 1f). Moreover, it is interesting to note that the selectivity of $2.5 \mathrm{~mol} / \mathrm{L}$ of $\left[\mathrm{mim}^{2}\left[\mathrm{HSO}_{4}\right]\right.$ towards delphinidin-3-O-monoglucoside (Fig. 1a) was greater than that of $2.5 \mathrm{~mol} / \mathrm{L}$ of $\left[\mathrm{C}_{2} \mathrm{mim}\right][\mathrm{Br}]$, while the reverse was found for all other monoglucosides. Furthermore, the solution of methanol showed better extraction efficiency than $2.5 \mathrm{~mol} / \mathrm{L}$ of $\left[\mathrm{C}_{4} \mathrm{mim}\right][\mathrm{Br}]$, where significantly higher mass fractions of delphinidin-3-O-monoglucoside, cyanidin-3-O-monoglucoside and petunidin-3-O-monoglucoside (Figs. $1 \mathrm{a}-\mathrm{c})$, and of the overall sum of anthocyanin-3-O-acetyl-monoglucosides (Fig. 1f) were found. The differences in selectivity were also observed between $2.5 \mathrm{~mol} / \mathrm{L}$ of $\left[\mathrm{SC}_{4} \mathrm{mim}\right]$ $\left[\mathrm{HSO}_{4}\right]$ and the methanol solution, since the former extracted higher mass fractions of all determined monoglucosides, except malvidin-3-O-monoglucoside and the overall sum of anthocyanin-3-O-monoglucosides.

Surprisingly, acylated derivatives of anthocyanins (Figs. $1 \mathrm{~g}$ and $\mathrm{h}$ ) followed a very different pattern from the one observed in anthocyanin-3-O-monoglucosides. For instance, the extraction efficiency of $2.5 \mathrm{~mol} / \mathrm{L}$ of [mim] $\left[\mathrm{HSO}_{4}\right]$ and the acidified aqueous solution of methanol was significantly lower $(p<0.05)$ than of other tested ILs. Despite the high efficiency in the extraction of total anthocyanins and individual anthocyanin-3-O-monogluco- sides, $2.5 \mathrm{~mol} / \mathrm{L}$ of $[\mathrm{mim}]\left[\mathrm{HSO}_{4}\right]$ showed significantly lower yields than all solvents in the extraction of anthocyanin-3-O-acetylmonoglucosides (Fig. 1g). A possible explanation for these results may be a very high acidity of this solvent, which can cause partial hydrolysis of malvidin-3-O-acetylmonoglucoside during the extraction of grape anthocyanins and lead to changes in their relative content (38). More interestingly, all ILs demonstrated higher selectivity for $p$-coumaroylmonoglucosides than the conventional methanol solution. Interestingly, $2.5 \mathrm{~mol} / \mathrm{L}$ of $\left[\mathrm{sC}_{4} \mathrm{mim}\right]\left[\mathrm{HSO}_{4}\right]$ that showed moderate extraction capacity of total anthocyanins was shown to be particularly efficient in the extraction of two acetylmonoglucosides (Fig. $1 \mathrm{~g}$ ), and together with $2.5 \mathrm{~mol} / \mathrm{L}$ of $\left[\mathrm{C}_{2} \mathrm{mim}\right][\mathrm{Br}]$ in the extraction of two $p$-coumaroylmonoglucosides (Fig. 1h).

\section{Conclusions}

A series of imidazolium-based ionic liquids (ILs) tested in our study showed the differences in the extraction efficiency of proanthocyanidins and anthocyanins from grape skin, depending on the anion and cation structure and concentration. The superiority of $\mathrm{Br}^{-}$and alkyl chain elongation of cation up to butyl and ethyl was established in the extraction yield of proanthocyanidins and anthocyanins, respectively, while the increase in their mass fraction affected the former more than the latter. The highest mass fraction of proanthocyanidins was extracted with $2.5 \mathrm{~mol} / \mathrm{L}$ of $\left[\mathrm{C}_{4} \mathrm{mim}\right][\mathrm{Br}]$. Some ILs extracted higher concentrations of total proanthocyanidins than the methanol solution, but could not compete with the two-step conventional acetone-methanol extraction. On the other hand, $2.5 \mathrm{~mol} / \mathrm{L}$ of $\left[\mathrm{C}_{2} \mathrm{mim}\right][\mathrm{Br}]$ followed by $2.5 \mathrm{~mol} / \mathrm{L}$ of $[\mathrm{mim}]\left[\mathrm{HSO}_{4}\right]$ extracted significantly higher mass fractions of total and free anthocyanin-3-O-monoglucosides than the conventional acidified methanol solution. Surprisingly, a different pattern was noticed for acylated derivatives, where affinity towards anthocyanin-3-O-acetylmonoglucosides decreased in the order $2.5 \mathrm{~mol} / \mathrm{L}$ of $\left[\mathrm{sC}_{4} \mathrm{mim}\right]$ $\left[\mathrm{HSO}_{4}\right]>\left[\mathrm{C}_{4} \mathrm{mim}\right][\mathrm{Br}]>\left[\mathrm{C}_{2} \mathrm{mim}\right][\mathrm{Br}]$, and finally for anthocyanin-3-(6-O-p-coumaroyl)monoglucosides in the order $2.5 \mathrm{~mol} / \mathrm{L}$ of $\left[\mathrm{C}_{2} \mathrm{mim}\right][\mathrm{Br}]>\left[\mathrm{sC}_{4} \mathrm{mim}\right]\left[\mathrm{HSO}_{4}\right]>\left[\mathrm{C}_{4} \mathrm{mim}\right][\mathrm{Br}]>$ $[\mathrm{mim}]\left[\mathrm{HSO}_{4}\right]$, with better performance than the conventional extraction. The distinctive affinities observed among ILs for structurally close compounds, anthocyanin-3-O-monoglucosides and their acylated derivatives, imply the possibility of the application of ILs as very selective solvents in the extraction of individual phenolic compounds.

\section{Acknowledgements}

Support from the University of Zagreb (Grant no. 0582261-7002223) is gratefully acknowledged.

\section{References}

1. Vidal S, Francis L, Guyot S, Marnet N, Kwiatkowski M, Gawel $R$, et al. The mouth-feel properties of grape and apple proanthocyanidins in a wine-like medium. J Sci Food Agr. 2003;83:564-73.

https://doi.org/10.1002/jsfa.1394 
2. Ćurko N, Kovačević Ganić K, Gracin L, Đapić M, Jourdes M, Teissedre PL. Characterization of seed and skin polyphenolic extracts of two red grape cultivars grown in Croatia and their sensory perception in a wine model medium. Food Chem. 2014;145:15-22. https://doi.org/10.1016/j.foodchem.2013.07.131

3. Chira K, Schmauch G, Saucier C, Fabre S, Teissedre PL. Grape variety effect on proanthocyanidin composition and sensory perception of skin and seed sannin extracts from Bordeaux wine grapes (Cabernet Sauvignon and Merlot) for two consecutive vintages (2006 and 2007). J Agric Food Chem. 2009; 57:545-53.

https://doi.org/10.1021/jf802301g

4. Castañeda-Ovando A, Pacheco-Hernández ML, Páez-Hernández ME, Rodríguez JA, Galán-Vidal CA. Chemical studies of anthocyanins: a review. Food Chem. 2009;113:859-71. https://doi.org/10.1016/j.foodchem.2008.09.001

5. Kruger MJ, Davies N, Myburgh KH, Lecour S. Proanthocyanidins, anthocyanins and cardiovascular diseases. Food Res Int. 2014;59:41-52. https://doi.org/10.1016/j.foodres.2014.01.046

6. Monagas M, Gómez-Cordovés C, Bartolomé B, Laureano O, Ricardo da Silva JM. Monomeric, oligomeric, and polymeric flavan-3-ol composition of wines and grapes from Vitis vinifera L. cv. Graciano, Tempranillo, and Cabernet Sauvignon. J Agric Food Chem. 2003;51:6475-81. https://doi.org/10.1021/jf030325+

7. García-Beneytez E, Cabello F, Revilla E. Analysis of grape and wine anthocyanins by HPLC-MS. J Agric Food Chem. 2003;51:5622-9. https://doi.org/10.1021/jf0302207

8. Revilla E, García-Beneytez E, Cabello F, Martín-Ortega G, Ryan JM. Value of high-performance liquid chromatographic analysis of anthocyanins in the differentiation of red grape cultivars and red wines made from them. J Chromatogr A. 2001;915:53-60. https://doi.org/10.1016/S0021-9673(01)00635-5

9. Ignat I, Volf I, Popa VI. A critical review of methods for characterisation of polyphenolic compounds in fruits and vegetables. Food Chem. 2011;126:1821-35. https://doi.org/10.1016/j.foodchem.2010.12.026

10. Naczk M, Shahidi F. Extraction and analysis of phenolics in food. J Chromatogr A. 2004;1054:95-111. https://doi.org/10.1016/j.chroma.2004.08.059

11. Kallithraka S, Garcia-Viguera C, Bridle P, Bakker J. Survey of solvents for the extraction of grape seed phenolics. Phytochem Analysis. 1995;6:265-7. https://doi.org/10.1002/pca.2800060509

12. Brouillard R, Dubois JE. Mechanism of the structural transformations of anthocyanins in acidic media. J Am Chem Soc. 1977;99:1359-64. https://doi.org/10.1021/ja00447a012

13. Lapornik B, Prošek M, Golc Wondra A. Comparison of extracts prepared from plant by-products using different solvents and extraction time. J Food Eng. 2005;71:214-22. https://doi.org/10.1016/j.jfoodeng.2004.10.036

14. Tang B, Bi W, Tian M, Row KH. Application of ionic liquid for extraction and separation of bioactive compounds from plants. J Chromatogr B. 2012;904:1-21. https://doi.org/10.1016/j.jchromb.2012.07.020

15. Han D, Row KH. Recent applications of ionic liquids in separation technology. Molecules. 2010;15:2405-26. https://doi.org/10.3390/molecules15042405

16. Earle MJ, Seddon KR. Ionic liquids. Green solvents for the future. Pure Appl Chem. 2000;72:1391-8. https://doi.org/10.1351/pac200072071391
17. Liu JF, Jönsson JÅ, Jiang GB. Application of ionic liquids in analytical chemistry. Trend Anal Chem. 2005;24:20-7. https://doi.org/10.1016/j.trac.2004.09.005

18. Berthod A, Ruiz-Ángel MJ, Carda-Broch S. Ionic liquids in separation techniques. J Chromatogr A. 2008;1184:6-18. https://doi.org/10.1016/j.chroma.2007.11.109

19. Huddleston JG, Visser AE, Reichert WM, Willauer HD, Broker GA, Rogers RD. Characterization and comparison of hydrophilic and hydrophobic room temperature ionic liquids incorporating the imidazolium cation. Green Chem. 2001;3: 156-64. https://doi.org/10.1039/B103275P

20. Cvjetko Bubalo M, Radošević K, Radojčić Redovniković I, Halambek J, Gaurina Srček V. A brief overview of the potential environmental hazards of ionic liquids. Ecotox Environ Safe. 2014;99:1-12. https://doi.org/10.1016/j.ecoenv.2013.10.019

21. Du FY, Xiao XH, Luo XJ, Li GK. Application of ionic liquids in the microwave-assisted extraction of polyphenolic compounds from medicinal plants. Talanta. 2009;78:1177-84. https://doi.org/10.1016/j.talanta.2009.01.040

22. Lou Z, Wang H, Zhu S, Chen S, Zhang M, Wang Z. Ionic liquids based simultaneous ultrasonic and microwave assisted extraction of phenolic compounds from burdock leaves. Anal Chim Acta. 2012;716:28-33. https://doi.org/10.1016/j.aca.2011.03.012

23. Du FY, Xiao XH, Li GK. Application of ionic liquids in the microwave-assisted extraction of trans-resveratrol from Rhizma Polygoni Cuspidati. J Chromatogr A. 2007;1140:56-62. https://doi.org/10.1016/j.chroma.2006.11.049

24. Liu X, Huang X, Wang Y, Huang S, Lin X. Design and performance evaluation of ionic liquid-based microwave-assisted simultaneous extraction of kaempferol and quercetin from Chinese medicinal plants. Anal Methods. 2013;5:2591-601. https://doi.org/10.1039/C3AY40202A

25. Zeng $\mathrm{H}$, Wang $\mathrm{Y}$, Kong J, Nie C, Yuan $\mathrm{Y}$. Ionic liquid-based microwave-assisted extraction of rutin from Chinese medicinal plants. Talanta. 2010;83:582-90. https://doi.org/10.1016/j.talanta.2010.10.006

26. Liu Y, Yang L, Zu Y, Zhao C, Zhang L, Zhang Y, et al. Development of an ionic liquid-based microwave-assisted method for simultaneous extraction and distillation for determination of proanthocyanidins and essential oil in Cortex cinnamomi. Food Chem. 2012;135:2514-21. https://doi.org/10.1016/j.foodchem.2012.07.001

27. Yang L, Sun X, Yang F, Zhao C, Zhang L, Zu Y. Application of ionic liquids in the microwave-assisted extraction of proanthocyanidins from Larix gmelini bark. Int J Mol Sci. 2012; 13:5163-78. https://doi.org/10.3390/ijms13045163

28. Bogel-Łukasik R, Nobre Gonçalves LM, Bogel-Łukasik E. Phase equilibrium phenomena in solutions involving tannins, flavonoids and ionic liquids. Green Chem. 2010;12: 1947-53. https://doi.org/10.1039/C0GC00308E

29. Bonhôte P, Dias AP, Papageorgiou N, Kalyanasundaram K, Grätzel M. Hydrophobic, highly conductive ambient-temperature molten salts. Inorg Chem. 1996;35:1168-78. https://doi.org/10.1021/ic951325x

30. Fehér C, Kriván E, Hancsók J, Skoda-Földes R. Oligomerisation of isobutene with silica supported ionic liquid catalysts. Green Chem. 2012;14:403-9. https://doi.org/10.1039/C1GC15989E

31. Lorrain B, Chira K, Teissedre PL. Phenolic composition of Merlot and Cabernet-Sauvignon grapes from Bordeaux vineyard for the 2009-vintage: comparison to 2006, 2007 and 2008 vintages. Food Chem. 2011;126:1991-9. https://doi.org/10.1016/j.foodchem.2010.12.062 
32. Ribéreau-Gayon P, Stonestreet E. Concentration of the tannins in red wine and determination of their structure. Chim Anal. 1966;48:188-96 (in French).

33. Ribéreau-Gayon P, Stonestreet E. Anthocyanin concentration in red wines. Bulletin de la Societé Chimique de France. 1965;9:2649-52 (in French).

34. STATISTICA v. 7, StatSoft, Inc., Electronic Statistics Textbook, Tulsa, OK, USA. Available from: http://www.statsoft.com/ textbook/.

35. Wei Z, Zu Y, Fu Y, Wang W, Luo M, Zhao C, Pan Y. Ionic liquids-based microwave-assisted extraction of active components from pigeon pea leaves for quantitative analysis. Sep Purif Technol. 2013;102:75-81.

https://doi.org/10.1016/j.seppur.2012.09.031
36. Pina F, Petrov V, Laia CAT. Photochromism of flavylium systems. An overview of a versatile multistate system. Dyes Pigm. 2012;92:877-89.

https://doi.org/10.1016/j.dyepig.2011.03.033

37. Fernandez D, Parola AJ, Branco LC, Afonso CAM, Pina F. Thermal and photochemical properties of 4'-hydroxyflavylium in water-ionic liquid biphasic systems. J Photochem Photobiol A. 2004;168:185-9.

https://doi.org/10.1016/j.jphotochem.2004.05.022

38. Revilla E, Ryan JM, Martín-Ortega G. Comparison of several procedures used for the extraction of anthocyanins from red grapes. J Agric Food Chem. 1998;46:4592-7.

https://doi.org/10.1021/jf9804692 